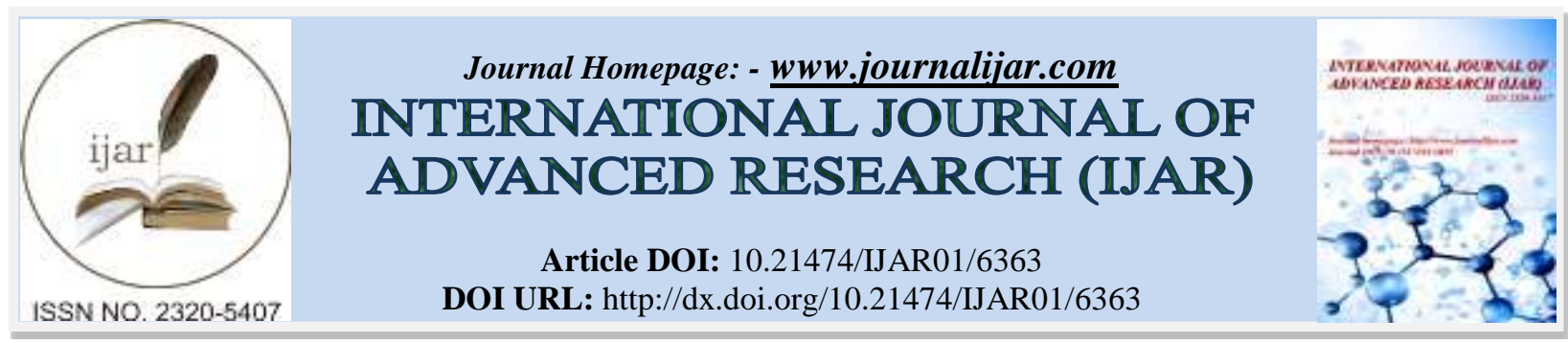

RESEARCH ARTICLE

\title{
ASSESSMENT OF KNOWLEDGE AND ATTITUDE TOWARDS CHILD OBESITY IN RIYADH POPULATION, SAUDI ARABIA.
}

\section{Abeer Ali Alkhalaf, Rawan Eid Alrwili And Hissah Ayidh Alshalawi.}

Medical interns.

\section{Manuscript Info}

Manuscript History

Received: 20 November 2017

Final Accepted: 22 December 2017

Published: January 2018

\begin{abstract}
Background: in saudi arabia, children's obesity is an alarming issue. The problem primarily relies on the ability of parents to recognize their child's overweight/obesity, and to be aware that obesity is a risk factor for long-term health issues. Several studies showed that many parents are not concerned about their children's body weight, because they either think too little of their child's body weight or believe that obesity is inherited, thus unmodifiable. Studies have suggested that targeting parents is a cost-effective strategy for the management of weightrelated problems in children. Objectives: this study was aimed to assess the level of knowledge of riyadh population regarding child obesity and parents attitude toward their children weight. Methods: community based cross sectional study that was conducted on riyadh's citizen aged 18 years and above, those who were under 18 years and health care workers were excluded from the study. Data was collected from 425 participants using interviewer-administered questionnaires and online surveys. Results: majority of participants (67\%) were between 18-29 years old, only (39\%) of the participants knew what body mass index is. $75 \%$ believe that weight gain in children is due to an unhealthy diet, while $(57 \%)$ believe it's a hereditary condition. (65\%) believe that obese children can have low self-esteem, majority of participants (97\%) believe that children's obesity has complications, where we note that (95\%)believe that obesity can be prevented.

Regarding parents, only (19\%) of the participants routinely measure their children's bmi, (35\%) believes that at least one of their children is obese, while $(30 \%)$ demonstrated that their children have shown concerns regarding their body image. Conclusion: majority of the participants did not know what bmi is. On the other hand, majority of them knew the risk factors for obesity, as well as the complications. They also knew that obesity can be prevented.
\end{abstract}

Copy Right, IJAR, 2018,. All rights reserved.

\section{Introduction:-}

Childhood obesity is a major health problem nationwide and internationally.1-2 The rising rate of childhood obesity in developing countries is as high as that of developed countries. Middle East countries are considered to have the highest rate of obeseloverweight children.3In Saudi Arabia, this problem is alarming among both male and female 
children.4 the prevalence of overweight and obesity in Saudi Arabia among school-aged children is calculable at $23 \%$ and $9 \%$, respectively. 5

Children's obesity prompts more serious medical conditions in adulthood than adult- onset obesity. Childhood weight has critical effect on many body systems such as endocrine, cardiovascular, and gastrointestinal. It causes high blood pressure, dyslipidemia, insulin resistance, and infertility. Moreover, obesity affects negatively on the child's psychological wellness, a child can have low self-esteem, depression, and anxiety.6 Obese children will probably stay obese in adulthood.7-9 Studies have demonstrated that up to half of obese adolescents end up as obese adults.10-11 furthermore, the cost of obesity-related illnesses in children have tripled from 1979 to 1999. 11

Increasing prevalence of obesity is attributed by many factors such as genetics, lifestyle behaviors, and environmental factors.13 Previous studies showed that the risk of a child becoming an adult obese is 3-10 times higher if one or both parents are obese. 11 This is maybe formed early in childhood, impacted by family practices and parental lifestyle. In another word, parents have an essential role in the formation of their child's dietary habits and lifestyle, 14 as they depend on their parents to support their well-being and promote positive development.15

A study in Saudi Arabia have shown that there were significant variations between parent's perception of weight compared to measured weight, and the percentage of misclassification by parents ranged from $20 \%$ to $35 \% .16$ Therefore, obesity prevention programs will not be of benefit if the parents cannot actively get involved.17 The benefit primarily relies on the ability of parents to recognize their child's overweight/obesity, and to be aware that obesity is a risk factor for long-term health issues. If the parents fail to identify their child's obesity, they would not take any action to improve their child's lifestyle, which may result in acceleration of the child's obesity problem.18 However, several studies showed that many parents are not concerned about their children's body weight, because they either think too little of their child's body weight or believe that obesity is inherited, thus unmodifiable.19-20-21 Studies suggest that targeting parents is a cost-effective strategy for the management of weight-related problems in children.22

Therefore, to prevent child obesity, we must identify the population believes about child obesity in Saudi Arabia, and parent's attitude and concerns about their children's weight.

\section{Objectives:-}

To assess the level of knowledge in Riyadh population about child obesity in many aspects such as (definition, causes, complications), and parents attitude toward child obesity in (Taking the problem into consideration, managing the problem)

\section{Methodology:-}

The study has been approved by the Institutional Review Board (IRB) in King Fahad Medical city, Riyadh. This community based cross-sectional study was conducted on 425 Saudi and non-Saudi adults aged 18 years and above in Riyadh city, subjects below 18 years and healthcare workers were excluded from the study. The study settings included shopping Malls, parks, hospitals, Coffee-shops, and online. Assuming a confidence level of $95 \%$ and confidence interval of $5 \%$, the sample size of 385 subjects was estimated by using stratified quota sampling. Informed consent was taken from all participants prior to participation in the study.

The study was based on two close-ended, structured, interviewer-administered and electronic questionnaires; one for the general population including parents consisting of two aspects; a) knowledge and believes regarding Body mass index, b) believes regarding the causes, complications of children's obesity, and problem overweight children might face, with total of 9 questions; while the other was for subjects who have children aged 0-18 years, consisting of an additional aspect i.e. their attitude regarding children's obesity, with total of 18 questions.

Both questionnaires were initially validated through a pilot test of 20 participants from the general population prior to administration. The whole process of questionnaire administration and collection took three weeks. These questionnaires were then distributed using quota sampling by research team to the corresponding study group.

All statistical analysis was conducted by SPSS software version 21.0. The descriptive statistics of studied sample were analyzed in terms of mean, standard deviations, median and interquartile range. Analysis of quantitative data 
by t-test and association of qualitative variables by chi-square test were conducted. P-value less than 0.05 was considered as statistically significant.

\section{Results:-}

This study population included Riyadh's citizen aged 18 years and above, a sample size of (425) was collected using interviewer-administered questionnaires and online surveys. Males represented $42.1 \%$ of total study participants while females represented $57.9 \%$. As seen in table (1), Majority of the participants were aged between 18 and 29 years old $(66.6 \%)$ and with higher educational level $(64 \%)$.

Table (2) demonstrate the knowledge regarding Body Mass index (BMI), $61 \%$ of the participant did not know what the BMI is, and 39\% knew what it is. Among those 39\% who knew, 74\% of them think they know the abnormal values. Regarding level of knowledge, Female gender had a higher level of knowledge with a statistical significant P-value (.003) as showing in table (2). The difference in education level had an impact on the level of knowledge with a P-value of (.000). Regarding the participants believes about BMI, $85 \%$ believe that BMI values are different for age and sex. While $15 \%$ believe that the BMI normal values are the same as in adults, $9 \%$ believe that the BMI value is not useful for children, and only $17 \%$ believe that the BMI value is not useful in children below two years of age.

Table (3) shows the participants believes regarding children Obesity. $58 \%$ of the participants believe that weight gain in children is usually hereditary, $75 \%$ believe that weight gain in children is due to an unhealthy diet, $23 \%$ of them believe that it will goes away by itself, as they grow up, and $34 \%$ of them think it is a problem requiring medical care.

Table (3) also shows that only $31 \%$ do believe that obesity in one of the parents is a risk factor for children obesity. Furthermore, only $14 \%$ of the participants think that the mother's gestational diabetes can cause obesity in children. And majority of the participants $(69 \%)$ believe that decrease physical activity and increase time spent on the computer, watching television, or playing video games is a risk factor for children obesity.

As shown in Table (3), Out of all participants, $41 \%$ think that being bullied is one of the problems that overweight children might face, $49 \%$ of them believe that overweight in adulthood is a problem, $65 \%$ believe that obese children might have problems with low self-esteem, and $49 \%$ believe that obese children will suffer from depression and anxiety later in life.

Majority of participants $(96.9 \%)$ think that obesity in children has complications. Figure (1) illustrates the participants' beliefs about those complications. $85 \%$ believe that Obstructive sleep apnea is one of the complications of childhood obesity, 59\% believe that hypertension is a complication of childhood obesity, 49\% believe that diabetes is a complications of childhood obesity, $44 \%$ believe that heart disease can also be caused by children obesity. Most of the participants $(95.3 \%)$ agreed that obesity in children can be prevented.

Table (4) shows the participants with children aged 0-18 years, We note that only $19 \%$ of the participants routinely measure the body mass of their children, 35\% of the participants believe that one or more of their children is obese, $30 \%$ of the participants demonstrated that their children have shown some concerns about their body image, $28 \%$ of the participants demonstrated that one of their children was picked on or made fun of for his/her body weight, and $84 \%$ of participants do encourage their children to eat healthy food and provide them with healthy eating options at home. Regarding Parents concerns, as Table (4) shows, $21 \%$ of the parents in our study were very concerned about their children weight, and $35.2 \%$ were concerned. The rest of parents were not concerned about their children weight.

Figure (2) shows the participants' distribution according to the extent of their children's participation in sports, recreational and play activities during the week. We note that $32 \%$ of children participate in sports, recreational and play activities from 2-4 hours, $14 \%$ from 5-8 hours, $17 \%$ more than 9 hours, $26 \%$ of them rarely engage in sports and recreational activities and toys.

Lastly, table (5) displays the participants' grouping according to how would they interfere if one of their children were obese. $76 \%$ of them will increase physical activity, decrease sedentary behaviors and change dietary habits. 
$21 \%$ will consult a dietitian, $12 \%$ will consult a physician, $7 \%$ will not do anything because they think that their child will eventually lose weight without interfering.

Table 1:- The participant's personal data.

\begin{tabular}{|l|l|l|l|}
\hline Personal Data & No. & $(\%)$ \\
\hline \multirow{3}{*}{ Gender } & Male & 179 & 42.1 \\
\cline { 2 - 4 } & Female & 246 & 57.9 \\
\hline \multirow{5}{*}{ Age } & Less than 18 & 24 & 5.6 \\
\cline { 2 - 4 } & $18-29$ & 283 & 66.6 \\
\cline { 2 - 4 } & $30-39$ & 53 & 12.5 \\
\cline { 2 - 4 } & $40-49$ & 49 & 11.5 \\
\cline { 2 - 4 } & 50 and more & 16 & 3.8 \\
\hline Educational level & Academic & 272 & 64.0 \\
\cline { 2 - 4 } & Secondary & 110 & 25.9 \\
\cline { 2 - 4 } & Preparatory & 36 & 8.5 \\
\cline { 2 - 4 } & Primary and less & 7 & 1.6 \\
\hline
\end{tabular}

Table 2:- the participants' distribution according to their knowledge of the body mass index.

\begin{tabular}{|c|c|c|c|}
\hline \multicolumn{3}{|c|}{ Do you know what is body mass index? } & \multirow{2}{*}{ P-value } \\
\hline & & Yes & \\
\hline \multirow{2}{*}{ Gender } & Male & $43(12 \%)$ & \multirow[t]{2}{*}{0.003} \\
\hline & Female & $88(24 \%)$ & \\
\hline \multirow[t]{4}{*}{ Educational level } & Academic & $104(28 \%)$ & \multirow[t]{4}{*}{$0.000 *$} \\
\hline & Secondary & $22(6 \%)$ & \\
\hline & Preparatory & $5(1 \%)$ & \\
\hline & Primary and less & $0(0 \%)$ & \\
\hline \multicolumn{3}{|c|}{ Do you think you know the abnormal values? } & \multirow[t]{2}{*}{ P-value } \\
\hline & & Yes & \\
\hline \multirow[t]{2}{*}{ Gender } & Male & $28(21 \%)$ & \multirow[t]{2}{*}{0.300} \\
\hline & Female & $65(50 \%)$ & \\
\hline \multirow{2}{*}{\multicolumn{2}{|c|}{$\begin{array}{l}\text { which one of the statements is right regarding body } \\
\text { mass index? }\end{array}$}} & \multicolumn{2}{|c|}{ I think it is correct } \\
\hline & & No. & $(\%)$ \\
\hline \multicolumn{2}{|c|}{ Normal values are different for age and sex. } & 362 & 85.2 \\
\hline \multirow{2}{*}{\multicolumn{2}{|c|}{$\begin{array}{l}\text { Normal values are the same as in adults. } \\
\text { It is not useful for children. }\end{array}$}} & 62 & 14.6 \\
\hline & & 38 & 8.9 \\
\hline \multicolumn{2}{|c|}{$\begin{array}{l}\text { It is not useful for children. } \\
\text { It is not useful in children below two years of }\end{array}$} & 73 & 17.2 \\
\hline
\end{tabular}

Table 3:- shows the participants' distribution according to their beliefs about weight gain in children.

\begin{tabular}{|l|l|l|}
\hline \multirow{2}{*}{$\begin{array}{l}\text { What beliefs do you have about overweight } \\
\text { in children? }\end{array}$} & I think it's correct \\
\cline { 2 - 3 } & No. & $(\%)$ \\
\hline it is caused by hereditary conditions & 246 & 57.9 \\
\hline it is caused by inappropriate diet & 319 & 75.1 \\
\hline it goes away by itself, as they grow up & 99 & 23.3 \\
\hline it is problem requiring medical care & 146 & 34.4 \\
\hline $\begin{array}{l}\text { Put next to the sentence that you think is } \\
\text { true regarding the risk factors of obesity in } \\
\text { children: }\end{array}$ & I think it's correct & $(\%)$ \\
\hline$\geq 1$ obese parents & 132 & 31.1 \\
\hline Decreased physical activity & 302 & 71.1 \\
\hline $\begin{array}{l}\text { Increased time spent watching television, } \\
\text { playing video games, or on the computer }\end{array}$ & 296 & 69.6 \\
\hline Maternal gestational diabetes & 60 & 14.1 \\
\hline What problems do you believe that & I think it's correct & \\
\hline
\end{tabular}




\begin{tabular}{|l|l|l|}
\hline overweight children can have or get? & No. & $(\%)$ \\
\hline Problems with being bullied & 174 & 40.9 \\
\hline Problems with overweight later in life & 209 & 49.2 \\
\hline Problems with having low self-esteem. & 274 & 64.5 \\
\hline $\begin{array}{l}\text { Problem with depression and anxiety later } \\
\text { in life. }\end{array}$ & 208 & 48.9 \\
\hline
\end{tabular}

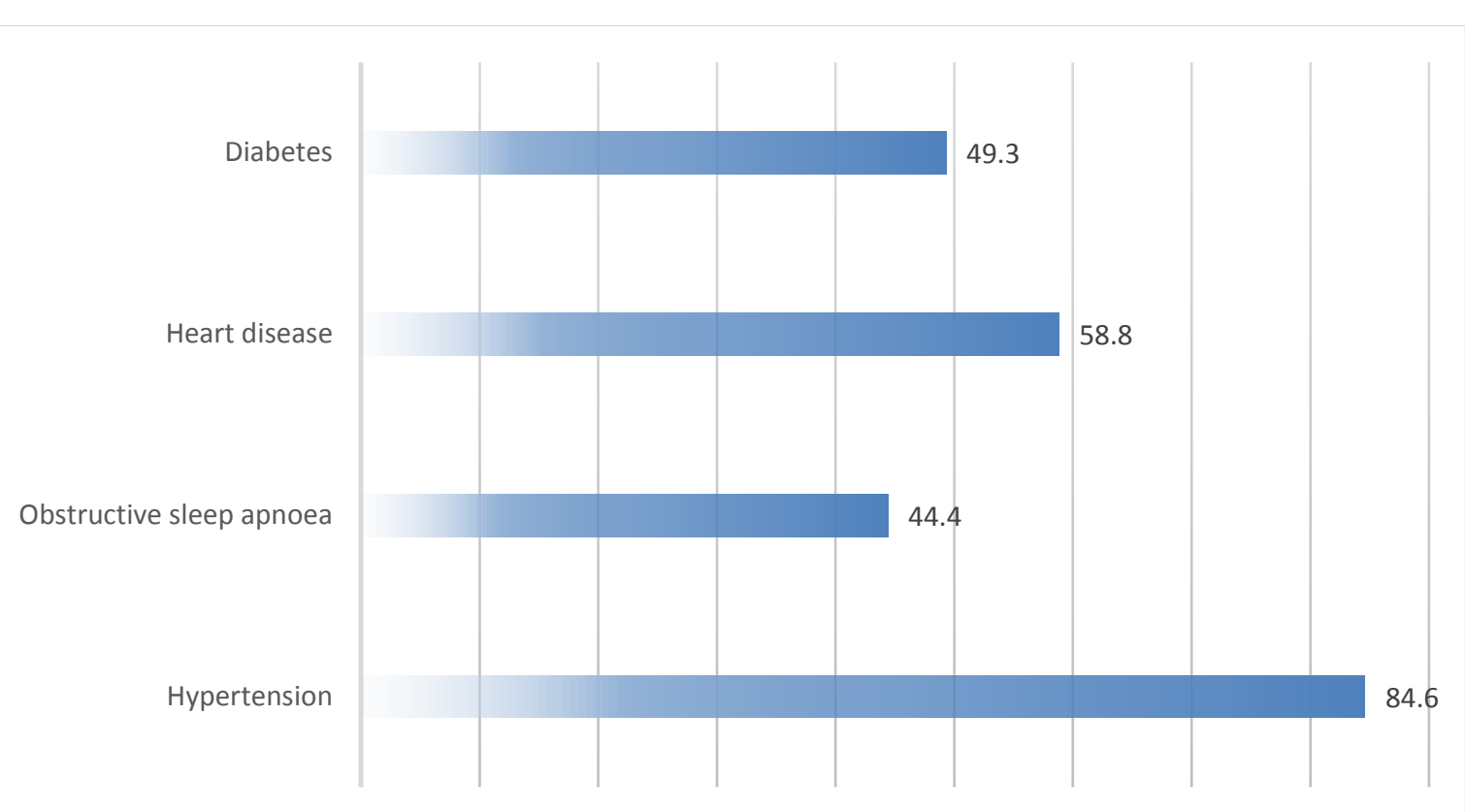

Figure 1:- illustrates the participants' beliefs about the complications of obesity in children.

Table 4:- shows the participants with children aged 0-18

\begin{tabular}{|l|l|l|}
\hline \multirow{2}{*}{$\mathrm{N}=210$} & Yes & $(\%)$ \\
\cline { 2 - 3 } & No. & 18.6 \\
\hline $\begin{array}{l}\text { Do you measure your children body } \\
\text { mass index routinely? }\end{array}$ & 39 & 34.8 \\
\hline $\begin{array}{l}\text { Do you believe one or more of your } \\
\text { children is overweight? }\end{array}$ & 73 & 29.5 \\
\hline $\begin{array}{l}\text { Has your child shown any concerns with } \\
\text { their body image? }\end{array}$ & 62 & 27.6 \\
\hline $\begin{array}{l}\text { Is your child picked on or made fun of } \\
\text { for his/her body weight? }\end{array}$ & 58 & 83.8 \\
\hline $\begin{array}{l}\text { Do you encourage eating healthy and } \\
\text { provide healthy meals for your children } \\
\text { routinely? }\end{array}$ & 176 & $(\%)$ \\
\hline $\begin{array}{l}\text { How concern is you about your child's } \\
\text { weight? }\end{array}$ & No. & 21.0 \\
\hline very concerned & 44 & 35.2 \\
\hline concerned & 74 & 18.1 \\
\hline not really concerned & 38 & 25.7 \\
\hline not a problem at all & 54 & \\
\hline
\end{tabular}




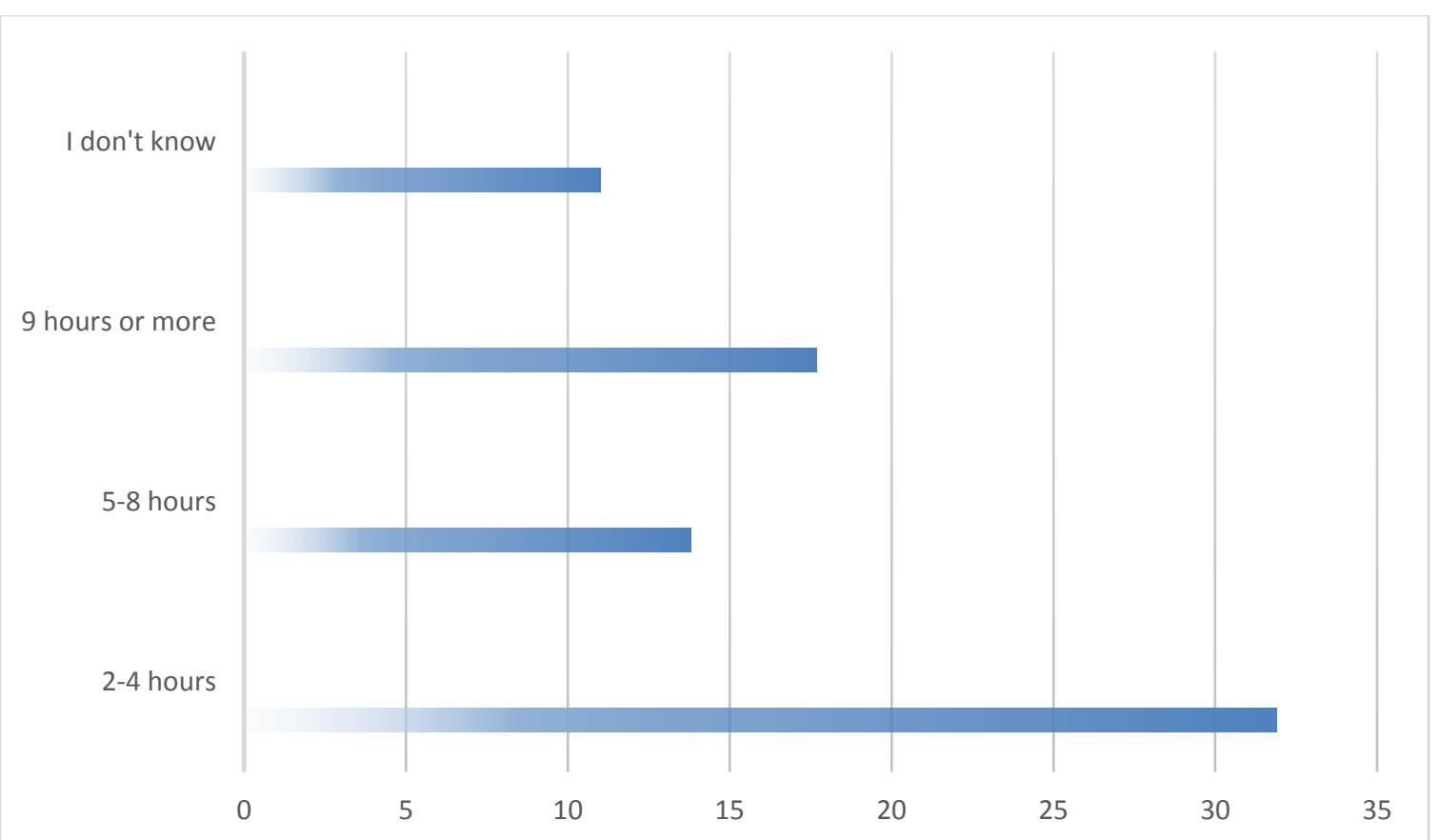

Figure 2:- shows the participants distribution according to the extent of their children's participation in sports, recreational and play activities during the week.

Table 5:- shows the participants' distribution according to how they will treat their children if they are obese.

\begin{tabular}{|l|l|l|}
\hline \multirow{2}{*}{} & Yes \\
\cline { 2 - 3 } & No. & $(\%)$ \\
\hline $\begin{array}{l}\text { Increase physical activity, decrease sedentary behaviors and } \\
\text { change dietary habits }\end{array}$ & 159 & 75.7 \\
\hline Nothing and she/he will lose weight eventually & & \\
\hline consult a dietitian & 15 & 7.1 \\
\hline Consult a physician & 44 & 21.0 \\
\hline
\end{tabular}

\section{Discussion:-}

This study was conducted to assess the knowledge about childhood obesity in Riyadh society in Saudi Arabia, and their attitude towards it. This study included 425 participants, about half of the participants have children aged 0-18 years.

The participants at this study showed a poor knowledge about Body Mass Index, Body-mass index (BMI) is a reasonably good measure of general adiposity $23, \mathrm{BMI} \geq 25=$ overweight; $\mathrm{BMI} \geq 30=$ obesity 24 . In our study only $38.6 \%$ participants knew what is body mass index, $74 \%$ of them think they know the abnormal values. This finding is consistent with Pakpour et al. study which was conducted in Iran and found that a large proportion of mothers do not have general knowledge on healthy body weight for children25. Another study reported that the majority (59.9\%) of primary care patients knew the meaning of BMI and that it is related to obesity, but there was little knowledge of BMI cutoff values26.

A research study reported that BMI is important for children, and self-assessment of the child's weight is unreliable, and it has been reported that children have a lower BMI than adults and it is different between boys and girls27. Most of the participants in the current study agreed that normal values are different for age and sex, and normal values aren't the same as in adults. This finding confirmed to Hatta et al. study findings 28 . While, $82.8 \%$ of our participants thought that BMI is not useful in children below two years of age, and according to Hatta et al. study findings, the BMI curve starts at the age of two years 28 . 
Regarding the knowledge about children overweight and obesity, our participants showed moderate level of knowledge. While, Mabiala et al. found at their study that knowledge of parents was satisfactory in most participants, among parents facing child and adolescent obesity in Congo29. And Qidwai et al., found in their study a significant level of understanding about obesity among the patients in Aga Khan University Hospital in Karachi30. This may be due to increased global awareness about obesity and its risks in general.

$58 \%$ of our participants thought that overweight in children is usually hereditary, while $23.3 \%$ thought that childhood obesity goes away by itself, as children grow up, also $34.4 \%$ thought that childhood obesity is problem requiring medical care. A study conducted by Herrera et al. found that, the current obesity epidemic does not have a purely genetic basis, although genetics do play a large role in susceptibility, and that the development of obesity has an evident environmental contribution 31 .

49.2\% of our participants agreed that overweight children might have Problems with overweight later in life, Pulgaron et al. reported that, being overweight in early childhood increases risk for later obesity 32 . There is evidence for the efficacy of family-based behavioral treatment to control weight and improve health outcomes 32 .

Concerning the risk factors of childhood obesity, the participants reveals a moderate level of knowledge about risk factors of childhood obesity. Most of the participants thought that both decreased physical activity and increased time spent watching television are risk factors of obesity in children. Boyse, 2009 suggested that parents should limit television-viewing time28. Television food advertising might influence children to increase their calorie intake33. But, only $31.1 \%$ of our participants thought that the obesity of one of parents at least could be a risk factor of obesity in children, according to Fuemmeler et al. study, parental obesity can influence the children appetitive traits thus increases the risk of childhood obesity 34 . Almost $14 \%$ of our participant thought that maternal gestational diabetes is a risk factor of obesity in children. While Zhao et al. concluded from their study that, Maternal gestational diabetes mellitus was associated with increased odds of childhood obesity at 9-11 years old but this association was not fully independent of maternal BMI35.

Obesity have many complications such as obstructive sleep apnoea 36, diabetes41, cardiovascular diseases 41 , cancer41, and hypertension 37 . About $96.9 \%$ of participants at the present study thought that there are complications of children obesity. Obstructive sleep apnoea was the most complication that mentioned by our participants, followed by hypertension, and then diabetes and heart disease by $85 \%, 59 \%, 49 \%$ and $44 \%$ respectively.

Most of our participants $95.3 \%$ thought that obesity in children can be prevented, A study concluded that childhood obesity problem can be reduced by educating parents and children about healthy nutrition and encouraging them to be physically active 38 .

Regarding parents' concerns towards obesity, our participants revealed poor practice towards obesity. This finding confirmed with Mabiala et al. finding that, obesity-related practices remain incorrect in most of the participants29. While a study conducted in Riyadh, Saudi Arabia by AlOtaibi et al., among Primary health care (PHC) physicians found that majority of PHC physicians displayed positive practices in managing childhood obesity 39 . The difference in results between our study and AlOtaibi et al. study is due to the difference in the target group, where our study targeted the general population but AlOtaibi et al. study targeted Primary health care (PHC) physicians. Also, Hatta et al. found good practices among mothers regarding childhood obesity in Malaysia28.

In the present study, 34.8\% of the participants thought that one or more of their children is obese. however, only $18.6 \%$ measure their children body mass index routinely. Reilly reported at his study that, self-assessment of the child's weight is unreliable24. So, parents should depend on body mass index to determine the extent of their children's obesity and not their own subjective assessment.

Physical activity is important to children's current and future health. It assists in the control of body weight by increasing energy expenditure, this is important in teaching children and young people how to achieve a healthy 'energy balance', and avoid developing adult obesity. It reduces the risk of developing premature cardiovascular disease, type-2 diabetes, metabolic syndrome and some cancers40. The Department of Health and Children's (DHC) 2009 physical activity guidelines state that children should participate in moderate to vigorous physical activity for at least 60 minutes every day (> 60 mins MVPA daily)40. Nevertheless, only $17.1 \%$ of our participants' children were doing physical activity 9 hours or more weekly, this is considered very worrying. 


\section{Conclusion:-}

This study showed that Riyadh's Population have a poor knowledge about Body Mass Index. They also have moderate level of knowledge about childhood overweight and obesity. As well as, they have a moderate level of knowledge about risk factors of childhood obesity. But they have revealed poor practice towards childhood obesity. Saudi children do not do enough physical activity which make them more susceptible to obesity. There is not enough attention from the Saudi parents in measuring the body mass index of their children, which will lead to decrease perception of parents towards their children's weight.

\section{Recommendations:-}

1. Conduct further studies on childhood obesity in Saudi Arabia to better understand the dimensions of the subject.

2. Conduct awareness campaigns and workshops to educate parents and children about the seriousness of obesity in childhood and how to prevent and deal with it.

3. Attention to the physical activities of children in schools.

4. Schools should be careful in providing healthy meals to children in schools and to limit the provision of fast meals full of fat and soft drinks for children.

5. Measure body mass index periodically for school children and alert parents of overweight children, and show them how to deal with this issue.

\section{References:-}

1. Karnik, S. and Kanekar, A. (2012) 'Childhood obesity: a global public health crisis.', International journal of preventive medicine. Medknow Publications, 3(1), pp. 1-7.

2. Dehghan M, Akhtar-Danesh N, Merchant AT. Childhood obesity, prevalence and prevention. Nutr J. $2005 ; 4: 24$.

3. James PT. Obesity: the worldwide epidemic. Clin Dermatol. 2004;22:276-80.

4. Alshammari Al-Shammari Yf, Y. F. F. (2014) 'Attitudes and practices of primary care physicians in the management of overweight and obesity in eastern saudi arabia.', International journal of health sciences. Qassim University, 8(2), pp. 151-8.

5. El Mouzan, M. I. et al. (2010) 'Prevalence of overweight and obesity in Saudi children and adolescents.', Annals of Saudi medicine. Medknow Publications, 30(3), pp. 203-8.

6. Amir H. PakpourI; Mir Saeed YekaninejadII; Hui ChenIII Mothers' perception of obesity in schoolchildren J. Pediatr. (Rio J.) vol.87 no.2 Porto Alegre Mar./Apr. 2011

7. Daniels SR, Arnett DK, Eckel RH, Gidding SS, Hayman LL, Kumanyika S, et al. Overweight in children and adolescents: pathophysiology, consequences, prevention, and treatment. Circulation. 2005;111:1999-2012.

8. Mossberg HO. 40-year follow-up of overweight children. Lancet. 1989;2:491-3.

9. Must A, Jacques PF, Dallal GE, Bajema CJ, Dietz WH. Long-term morbidity and mortality of overweight adolescents. A follow-up of the Harvard Growth Study of 1922 to 1935. N Engl J Med. 1992;327:1350-

10. Power C, Lake JK, Cole TJ. Measurement and long term health risks of child and adolescent fatness. Int J Obes Relat Metab Disord. 1997;21:507-26.

11. Freedman DS, Dietz WH, Srinivisan SR, Berenson GS. The relation of overweight to cardiovascular risk factors among children and adolescents: The Bogalusa Heart Study. Pediatrics. 1999;103:1175-82.

12. Wang G, Dietz WH. Economic burden of obesity in youths aged 6 to 17 years: 1979-1999. Pediatrics. 2002;109:E81-1.

13. Sahoo, K. et al. (2015) 'Childhood obesity: causes and consequences.', Journal of family medicine and primary care. Medknow Publications, 4(2), pp. 187-92. doi: 10.4103/2249-4863.154628.

14. Lindsay AC, Sussner KM, Kim J, Gortmaker S. The role of parents in preventing childhood obesity. Future Child. 2006;16:169-86.

15. Salama, A., Elhawary, D. and El-Nmer, F. (2014) 'Nutritional knowledge, attitude, and practice of parents and its impact on growth of their children',Menoufia Medical Journal. Medknow Publications and Media Pvt. Ltd., 27(3), p. 612. doi: 10.4103/1110-2098.145529.

16. Al-Mohaimeed, A. A. (2016) 'Parents' perception of children's obesity, in Al-Qassim, Saudi Arabia.', Journal of family \& community medicine. Medknow Publications, 23(3), pp. 179-83. doi: 10.4103/2230-8229.189134.

17. Baughcum AE, Chamberlin LA, Deeks CM, Powers SW, Whitaker RC. Maternal perceptions of overweight preschool children. Pediatrics. 2000;106:1380-6.

18. Jain A, Sherman SN, Chamberlain LA, Carter Y, Powers SW, Whitaker RC. Why don't low-income mothers worry about their preschoolers being overweight? Pediatrics. 2001;107:1138-46. 
19. He M, Evans A. Are parents aware that their children are overweight or obese? Do they care? Can Fam Physician. 2007;53:1493-9.

20. Myers S, Vargas Z. Parental perceptions of the preschool obese child. Pediatr nurs. 2000;26:23-30.

21. Etelson D, Brand DA, Patrick PA, Shirali A. Childhood obesity: do parents recognize this health risk? Obes Res. 2003;11:1362-8.

22. Golan M. Parents as agents of change in childhood obesity-from research to practice. Int J Pediatr Obes. 2006;1:66-76.

23. Prospective Studies Collaboration. "Body-mass index and cause-specific mortality in 900000 adults: collaborative analyses of 57 prospective studies." The Lancet 373.9669 (2009): 1083-1096.

24. Reilly, John J. "Childhood obesity: An overview." Children \& Society21.5 (2007): 390-396.

25. Pakpour, Amir H., Mir Saeed Yekaninejad, and Hui Chen. "Mothers' perception of obesity in schoolchildren: a survey and the impact of an educational intervention." Jornal de pediatria 87.2 (2011): 169-174.

26. Post, Robert E., et al. "Patient understanding of body mass index (BMI) in primary care practices: a two-state practice-based research (PBR) collaboration." The Journal of the American Board of Family Medicine 28.4 (2015): 475-480.

27. Reilly, John J. "Childhood obesity: An overview." Children \& Society21.5 (2007): 390-396.

28. Hatta, Nur Khairul Bariyyah Mohd, et al. "Knowledge, Attitude and Practices among Mothers Regarding Childhood Obesity at Kuantan, Malaysia." International Medical Journal 24.2 (2017): 200-204.

29. Mabiala Babela, Jean Robert, et al. "Knowledge, Attitudes, and Practices of Parents Facing Child and Adolescent Obesity in Brazzaville, Congo." Global pediatric health 3 (2016): 2333794X16675546.

30. Qidwai, Waris, and Syed Iqbal Azam. "Knowledge, attitude and practice regarding obesity among patients, at Aga Khan University Hospital, Karachi." J Ayub Med Coll Abbottabad 16.3 (2004): 32-4.

31. Herrera, Blanca M., and Cecilia M. Lindgren. "The genetics of obesity." Current diabetes reports 10.6 (2010): 498-505.

32. Pulgaron, Elizabeth R., and Alan M. Delamater. "Obesity and type 2 diabetes in children: epidemiology and treatment." Current diabetes reports 14.8 (2014): 508.

33. Goris, Janny M., et al. "Television food advertising and the prevalence of childhood overweight and obesity: a multicountry comparison." Public health nutrition 13.7 (2010): 1003-1012.

34. Fuemmeler, Bernard F., et al. "Parental obesity moderates the relationship between childhood appetitive traits and weight." Obesity21.4 (2013): 815-823.

35. Zhao, Pei, et al. "Maternal gestational diabetes and childhood obesity at age 9-11: results of a multinational study." Diabetologia59.11 (2016): 2339-2348.

36. Schwartz, Alan R., et al. "Obesity and obstructive sleep apnea: pathogenic mechanisms and therapeutic approaches." Proceedings of the American Thoracic Society 5.2 (2008): 185-192.

37. Re, Richard N. "Obesity-related hypertension." The Ochsner Journal9.3 (2009): 133-136.

38. Karnik, Sameera, and Amar Kanekar. "Childhood obesity: a global public health crisis." International journal of preventive medicine 3.1 (2012): 1.

39. AlOtaibi, Faiza Nasser, et al. "Childhood and adolescent obesity: Primary Health Care Physicians' perspectives from Riyadh, Saudi Arabia." Pakistan journal of medical sciences 33.1 (2017): 100.

40. Woods, Catherine, Niall Moyna, and Aoileann Quinlan. "The children's sport participation and physical activity study (CSPPA study)." (2010).

41. Mahajan, Preetam B., et al. "Study of childhood obesity among school children aged 6 to 12 years in union territory of Puducherry." Indian journal of community medicine: official publication of Indian Association of Preventive \& Social Medicine 36.1 (2011): 45. 